\title{
Oral health related quality of life among HIV positive patients attending two HIV outpatient clinics in Nigeria - a cross sectional study
}

\author{
Kehinde Adesola Umeizudike ${ }^{1,3}$, Babatope Bamidele Osagbemiro², Opeyemi Oluwayemisi \\ Daramola $^{3}$, Titilope Adenike Adeyemo ${ }^{4}$
}

1. Department of Preventive Dentistry, Faculty of Dental Sciences, College of Medicine, University of Lagos, Idi-Araba, Lagos State. Email: kumeiz09@gmail.com

2. Department of Preventive Dentistry, University of Port-Harcourt Teaching Hospital, Rivers State.

Email: topegraphics03@yahoo.co.uk

3. Department of Preventive Dentistry, Lagos University Teaching Hospital, Idi Araba, Lagos State. Email: opeyemidaramola1985@gmail.com

4. Department of Haematology \& Blood transfusion, College of Medicine, University of Lagos, Idi-Araba, Lagos State. Email: taadeyemo@cmul.edu.ng

\begin{abstract}
Background: The human immunodeficiency virus infection remains a devastating disease of public health importance. Objectives: To assess the association between oral health and quality of life and the factors affecting the oral health related quality of life among HIV positive patients in Nigeria.

Methods: This was a cross sectional study of HIV positive patients attending two HIV outpatient clinics in Nigeria. Impact of oral health on quality of life was assessed using the OHIP-14. Oral health status was assessed by the DMFT and Simplified OHI indices. Level of significance was set at $\mathrm{p}<0.05$.

Results: Three hundred and fifty-two patients were seen, $64.2 \%$ being females. Prevalence of impact was $8.5 \%$; and the mean OHIP scores was 8.05 9.54. Highest impact was "painful aching" 67(19.1\%) with the domain of physical pain scoring the highest mean impact of 2.32. Most patients $(88.6 \%)$ were on HAART. Following logistic regression, after controlling for potential confounders, independent factors associated with poor OHRQoL were perceived need for dental treatment, HAART use, and higher DMFT ( $\mathrm{p}<0.05)$.

Conclusion: The domain of physical pain had the highest impact, while perceived need for dental treatment, HAART use
\end{abstract} and higher caries index were contributory to poor OHRQoL.

Keywords: HIV infection, Oral health, OHRQoL.

DOI: https://dx.doi.org/10.4314/ahs.v21i2.11

Cite as: Umeizudike KA, Osagbemiro BB, Daramola OO, Adeyemo TA. Oral health related quality of life among HIV positive patients attending two HIV outpatient clinics in Nigeria - a cross sectional study. Afri Health Sci. 2021;21(2). 566-575. https: / dx.doi.org/ 10.4314/ abs.v21i2.11

\section{Introduction}

The human immunodeficiency virus (HIV) infection has been one of the most devastating diseases of public health importance affecting mankind in the past few decades. Not only has the virus infected a huge population of people (estimated to be 75 million) globally since the beginning of the pandemic, it has also resulted in the death of at least 32 million people from Acquired

\section{Corresponding author:}

Kehinde Adesola Umeizudike, Department of Preventive Dentistry, Faculty of Dental Sciences, College of Medicine, University of Lagos, Idi-Araba, Lagos State

Phone no.

Email: kumeiz09@gmail.com
Immunodeficiency syndrome (AIDS)-related illness$e^{1}$. Currently, the number of HIV infections stands at about 37.9 million people ${ }^{1}$ with a global prevalence of $0.8 \%$ among adults ${ }^{2}$. The vast majority of people living with HIV/AIDS (PLWHA) reside in low- and middleincome countries ${ }^{3}$. The epicentre of the HIV infection is sub-Saharan Africa, which bears most of the burden, affecting approximately $68 \%$, which is an estimated 25.7 million people ${ }^{4}$. This is alarming because of the restricted resources in Africa where the HIV infection is one of the leading causes of mortality.

The current prevalence rate of HIV in Nigeria is $1.4 \%$, which is lower than the $3.9 \%$ previously reported in $2008^{5}$. This has been attributed to better surveillance and access to antiretroviral treatment ${ }^{5}$. Despite the work is properly cited. 
lower rate, Nigeria still has the largest number of PLWHA in Africa and has the second largest HIV epidemic globally due to huge number of people infected, an estimated 1.9 million (adults aged $15-49$ years) 5 . HIV infection thus contributes to the burden of disease and remains a significant public health threat for Nigerians ${ }^{5}$. The quality of life of PLWHA may be impacted by factors such as poor oral health, which has been known to be a contributing factor to the development of opportunistic infections in persons living with HIV/AIDS ${ }^{6}$. Oral manifestations of HIV infection are well established in the literature and may occur in over $50 \%$ of HIV/AIDS patients ${ }^{7}$. These oral lesions often present as early signs and symptoms of the disease and most commonly include HIV gingivitis and periodontitis, fungal and other opportunistic infections as well as $\mathrm{Ka}$ posi's sarcoma ${ }^{7,8,9}$. Whilst, lesions such as candidiasis and hairy leukoplakia are considered as prognostic factors of HIV infection, reports indicate that concurrent existence of multiple and variable oral lesions is accompanied by poor prognosis of HIV infection ${ }^{10}$.

The advent of antiretroviral therapy (ART) particularly the highly active antiretroviral therapy (HAART) has improved the quality of life of HIV positive patients and has reduced to a very large extent the prevalence of oral lesions in HIV infected patients ${ }^{11,12}$. A lower prevalence of some oral lesions have also been reported in Nigeria ${ }^{13}$. A reduced rate of salivary flow has been reported on PLWHA on HAART which may be related to the type of $\mathrm{ART}^{14}$. Improved access to ART has significantly increased life expectancy for HIV positive persons ${ }^{15}$. The scale-up HIV response by the Nigerian government to include about 1 million patients on HAART across 1500 treatment sites is encouraging ${ }^{5}$, and would no doubt prolong the life expectancy of PLWH in Nigeria. However, some oral lesions in HIV infection appear to predict disease progression and may signify the failure of HAART and can substantially contribute to deterioration in the quality of life of HIV infected patients ${ }^{16}$.

The HIV-1 infection has an independent and negative impact on the oral HRQoL ${ }^{17}$. The impact of HIV/ AIDS and oral disease on the Quality of Life affects physical and emotional well-being, social support systems, and life roles ${ }^{7,18}$. A variety of instruments have been developed to measure the oral health quality of life $^{19}$. The Oral Heath Impact Profile (OHIP), in both the long (OHIP-49) and short forms (OHIP-14), is one of the most commonly used instruments to evaluate the impact of different oral disorders on well-being. It was developed by Slade and Spencer in 1994 and contains seven dimensions that are based on Locker's theoretical model of oral health ${ }^{20}$. The dimensions are: functional limitation, physical pain, psychological discomfort, physical disability, psychological disability, social disability and handicap ${ }^{21}$. Patients with more severe AIDS manifestations had more oral symptoms, functional limitations, emotional and social well being related to their oral health ${ }^{18}$. HIV-positive patients with some oral lesions experienced greater social impacts which were associated with poorer oral health related quality of $\operatorname{life}^{22}$. In addition to the influence of social class, the perception of the influence of oral health on the quality of life was also shown to be influenced by age and sex in the HIV positive patients ${ }^{7}$. A poorly functioning dentition can complicate the management of medical conditions and create or exacerbate nutritional and psychosocial problems. Oral health care may improve the health related quality of life in HIV/AIDS patients ${ }^{23}$.

As people are living longer with HIV, the study on their quality of life has emerged as an important factor in their overall management ${ }^{24}$. This was also highlighted by the Centers for Disease Control and Prevention (CDC) whose goal is to improve health outcomes of PLWHA by extending life and its quality ${ }^{25}$. Although, several studies have been carried out on oral lesions among HIV positive patients with and without HAART therapy in Nigeria ${ }^{8,9,16}$, to the best of our knowledge, there is no published study on the oral health related quality of life (OHRQoL) among PLWHA in Nigeria. The aim of this study was therefore to determine the association between oral health and the quality of life and the factors affecting OHRQoL among HIV positive patients in Nigeria.

\section{Methodology}

This cross-sectional, descriptive study was part of a larger study among HIV positive patients attending two HIV dedicated out-patient clinics. The HIV status of the patients was assessed and confirmed using the WHO recommended HIV testing algorithm. The HIV clinics selected for the study were located at the Lagos University Teaching Hospital (LUTH) [Lagos state, South-west Nigeria] and the University of Port-Harcourt Teaching Hospital (UPTH) (Rivers state, Southsouth Nigeria]. 
The HIV clinic in LUTH was selected being one of the foremost HIV Treatment centres in Nigeria, coupled with the fact that Lagos is a cosmopolitan state with diverse ethnic representation. The HIV clinic in Rivers state was selected because the state had the highest HIV prevalence rate in Nigeria during the study period.

The participants were recruited into the study between June and October, 2016 to assess the factors associated with their oral health related quality of life. The inclusion criteria were subjects $\geq 17$ years, and diagnosis of HIV infection of at least one-year's duration. Patients who were psychologically compromised, had neurological deficit or who refused to give their informed consent were excluded from the study. The questionnaires were kept anonymous and all information collected during the study were treated as confidential. The sample size was calculated using the Fisher's formula for both study centres. A convenience sampling method was used to recruit consecutive subjects who presented for their scheduled outpatient appointment at the HIV clinic into the study until the desired sample size was achieved.

Ethical approval was sought and obtained from the Institutional Review Committees of both institutions before commencing the study. Data was collected with the aid of structured, self-administered questionnaires. Information was obtained on respondents' socio-demographic details, past dental visits, self-rated oral health and self-assessed perceived treatment needs. A detailed medical history was also obtained including their CD4 $+\mathrm{T}$ lymphocyte counts, and the length of time since their initial HIV/AIDS diagnosis. The subjects were categorized into different socio-economic status (SES) by combining education and occupation according to Oyedeji ${ }^{26}$. The scores from both categories were added and an average derived by dividing by 2 . The subjects were then categorized into upper SES (1), middle SES (2 and 3), and lower SES (4 and 5).

Impact of oral health on quality of life was assessed using questions from the shortened version of the Oral Health Impact Profile (OHIP-14) ${ }^{20}$. The OHIP14 questionnaire consists of 14 statements that have been rephrased as questions under 7 broad dimensions or domains as follows: functional limitation, physical pain, psychological discomfort, physical disability, psychological disability, social disability and handicap. Subjects were asked to indicate on a five-point Likert scale how frequently they experienced each problem within a reference period (1 year). Response categories for the five-point scale were: "Very often", "Fairly often", “Occasionally", "Hardly ever" and "Never". Oral examination was carried out under natural lighting by examiners who had been previously calibrated. Oral health status was assessed by the DMFT (Decayed, Missing \& Filled Teeth) index and the Simplified Oral Hygiene Index (OHI-S) by Greene \& Vermillion ${ }^{27}$. The DMFT index values were graded as Very mild $(<5.0)$, mild $(5.0-8.9)$, Moderate (9.0-13.9), severe $(>13.9)^{28}$. Oral lesions associated with HIV/AIDS were documented using the presumptive diagnosis of the EC-Clearinghouse, 1993 guidelines on the diagnostic criteria for classifying oral lesions in $\mathrm{HIV}^{29}$.

\section{Data Analysis}

The analysis was done using the SPSS version 20 (IBM SPSS Armonk, New York) software. For data entry, responses on the five-point Likert scale were coded 0 (never), 1(hardly ever), 2(occasionally), 3(fairly often) or 4(very often). The severity of impact in each individual is the sum of all ordinal response codes. The severity may range from 0 to 56 and the mean severity score is the mean OHIP-14 score. Based on the responses, the prevalence of impact (the percentage of participants responding as 'fairly often' or 'very often' to one or more items) was also determined. Given the significant skewness of the distribution of OHIP-14 scores, the subjects' OHIP-14 scores were dichotomized as less than or greater than the median value for the studied population, with OHIP-14 scores greater than the median score representing a poor OHRQoL ${ }^{30}$.

Chi-square tests and Fisher's exact tests were used where appropriate to determine associations. Variables that were statistically significant in the Chi-square and spearman correlation tests were entered into a logistic regression model to determine the factors that were significantly independently associated with a poor OHRQoL. Results were considered statistically significant if the P-value was $<0.05$.

\section{Results}

A total of three hundred and fifty-two (352) subjects from the two study centres (LUTH and UPTH) participated in the study.

\section{Socio-demographic data}

The mean age was 42.5 years $\pm 9.4(\mathrm{SD})$, with most subjects $(60.8 \%)$ being at least 40 years old. About twothirds, $226(64.2 \%)$ of the subjects were females. One hundred and sixty-two (46\%) subjects were from the 
Igbo ethnic group in the South east zone. Significant associations were found in the occupation $(\mathrm{P}<0.001)$, socioeconomic status $(\mathrm{P}=0.002)$, and geopolitical zone $(\mathrm{P}<0.001)$ of the two study centres. The socio-demographic characteristics are shown in Table 1.

Table 1: Socio-demographic characteristics of PLWHA by the HIV clinics attended

\begin{tabular}{|c|c|c|c|c|}
\hline Characteristic & $\begin{array}{l}\text { LUTH } \\
\text { N (\%) } \\
\end{array}$ & $\begin{array}{l}\text { UPTH } \\
\text { N (\%) } \\
\end{array}$ & \begin{tabular}{l|} 
Total \\
$\mathbf{N}(\%)$ \\
\end{tabular} & P-value \\
\hline \multicolumn{5}{|l|}{ Age group } \\
\hline$\leq 19$ & $1(0.4)$ & $2(2.0)$ & $3(0.9)$ & $<0.001^{*}$ \\
\hline $20-39$ & $80(31.5)$ & $55(56.1)$ & $135(38.4)$ & \\
\hline $40-59$ & $160(63.0)$ & $40(40.8)$ & $200(56.8)$ & \\
\hline$\geq 60$ & $13(5.1)$ & $1(1.0)$ & $14(4.0)$ & \\
\hline \multicolumn{5}{|l|}{ Gender } \\
\hline Female & $169(66.5)$ & $57(58.2)$ & $226(64.2)$ & 0.179 \\
\hline Male & $85(33.5)$ & $41(41.8)$ & $126(35.8)$ & \\
\hline \multicolumn{5}{|l|}{ Educational level } \\
\hline$\leq$ Primary & $48(18.9)$ & $18(18.4)$ & $66(18.8)$ & 0.378 \\
\hline Secondary/Diploma & $139(54.7)$ & $47(47.9)$ & $186(52.8)$ & \\
\hline$\geq$ University & $67(26.4)$ & $33(33.7)$ & $100(28.4)$ & \\
\hline \multicolumn{5}{|l|}{ Occupation (1>3) } \\
\hline 1 & $44(17.3)$ & $46(46.9)$ & $90(25.6)$ & $<0.001 *$ \\
\hline 2 & $186(73.2)$ & $41(41.9)$ & $227(64.5)$ & \\
\hline 3 & $24(9.5)$ & $11(11.2)$ & $35(9.9)$ & \\
\hline \multicolumn{5}{|l|}{ Socioeconomic } \\
\hline Status Upper & $63(24.8)$ & $43(43.8)$ & $106(30.1)$ & $0.002 *$ \\
\hline Middle & $179(70.5)$ & $52(53.1)$ & $231(65.6)$ & \\
\hline Lower & $12(4.7)$ & $3(3.1)$ & $15(4.3)$ & \\
\hline \multicolumn{5}{|l|}{ Geopolitical Zone } \\
\hline South West & $84(33.1)$ & $5(5.1)$ & $89(25.3)$ & $<0.001 *$ \\
\hline South South & $50(19.7)$ & $34(34.7)$ & $84(23.9)$ & \\
\hline South East & $104(40.9)$ & $59(59.2)$ & $162(46.0)$ & \\
\hline North (NW, NC, NE) & $16(6.3)$ & $1(1.0)$ & $17(4.8)$ & \\
\hline
\end{tabular}

\section{Clinical findings among the PLWHA}

Oral lesions associated with HIV/AIDS were observed in $21(5.9 \%)$ subjects with linear gingival erythema being the most common oral lesion (1.99\%), followed by can- didiasis $(1.70 \%)$. See Figure 1. The mean CD4+ T lymphocyte count was $552.4 \pm 237.8$ cells $/ \mathrm{mm}^{3}$ ( $\mathrm{n}=140$ ). The DMFT grade was mild in $72(20.5 \%)$ and very mild in $52(14.8 \%)$. The mean DMFT was $1.8 \pm 2.8$, while the

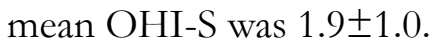


Oral health related quality of life (OHRQoL)

The prevalence of impact caused by oral health problems measured by the OHIP-14 in the preceding 12 months was $8.5 \%$ among the PLWHA.

The mean $( \pm \mathrm{SD})$ and median(range) OHIP-14 scores were $8.05 \pm 9.54$ and 5.0(0-56), respectively.

Table 2 shows the prevalence of impact and the mean severity score for each of the OHIP-14 item. The prevalence of impact was highest for the "painful aching" item where $67(19.1 \%$ ) of the subjects reported that they had an impact within the last one year. The other common oral health impact was caused by uncomfortable chewing (17.1\%) and avoidance of certain foods $(10.8 \%)$. With regard to mean domain scores, the highest mean impact was obtained in the domain of physical pain with an overall mean impact of 2.32 .

Table 2: Prevalence of oral health impact and mean severity score for each item

\begin{tabular}{lll}
\hline OHIP domain and items & $\begin{array}{l}\text { Frequency } \\
(\%)\end{array}$ & Mean severity score (SD) \\
\hline $\begin{array}{l}\text { Functional limitation } \\
\text { 1.Trouble pronouncing words }\end{array}$ & $23(6.6)$ & $0.41(0.97)$ \\
2. Worsened taste & $25(7.1)$ & $0.51(1.03)$ \\
Physical pain & & \\
3. Painful aching & $67(19.1)$ & $1.28(1.37)$ \\
4. Uncomfortable chewing & $60(17.1)$ & $1.04(1.36)$ \\
Physical disability & & \\
5. Diet unsatisfactory & $28(8.0)$ & $0.53(1.04)$ \\
6. Avoidance of certain foods & $38(10.8)$ & $0.60(1.18)$ \\
Psychological discomfort & & \\
7. Self-conscious & $37(10.5)$ & $0.67(1.15)$ \\
8. Uncomfortable about & $28(8.0)$ & $0.62(1.11)$ \\
appearance & & \\
Psychological disability & & \\
9. Difficult to relax & $32(9.1)$ & $0.65(1.14)$ \\
10. Been embarrassed & $19(5.4)$ & $0.40(0.93)$ \\
Social disability & & \\
11. Irritable with others & $15(4.3)$ & $0.32(0.84)$ \\
12. Difficulty with daily & $16(4.5)$ & $0.30(0.81)$ \\
activities & & \\
Handicap & & $0.37(0.87)$ \\
13. Unable to function & $16(4.6)$ & $0.28(0.80)$ \\
14. Life less satisfying & $14(4.0)$ & \\
\hline
\end{tabular}

About a quarter of the subjects $87(24.7 \%)$ had a of the OHRQoL were 183(52\%) while those with poor self-reported medical condition with their HIV status, OHRQoL were 169(48\%). Poor OHRQoL was associalthough there was no significant association with the ated with socioeconomic status $(\mathrm{P}=0.028)$ and the use OHRQoL ( $\mathrm{P}=0.733)$. Subjects with less/good impact of HAART $(\mathrm{P}=0.020)$. (Table 3).

Table 3: Association of socio-demographic characteristics with poor OHRQoL

\begin{tabular}{|c|c|c|c|c|}
\hline & Good OHRQoL & \multicolumn{2}{|c|}{ Poor OHRQoLTotal } & \multirow[b]{2}{*}{ P-value } \\
\hline & $\mathbf{N}(\%)$ & $\mathbf{N}(\%)$ & $\mathbf{N}(\%)$ & \\
\hline \multicolumn{5}{|l|}{ Age group } \\
\hline$\leq 19$ & $1(33.3)$ & $2(66.7)$ & $3(0.9)$ & 0.804 \\
\hline $20-39$ & $73(54.1)$ & $62(45.9)$ & $135(38.4)$ & \\
\hline $40-59$ & $101(50.5)$ & $99(49.5)$ & $200(56.8)$ & \\
\hline$\geq 60$ & $8(57.1)$ & $6(42.9)$ & $14(4.0)$ & \\
\hline \multicolumn{5}{|l|}{ Gender } \\
\hline Male & $68(54.0)$ & $58(46.0)$ & $126(35.8)$ & 0.656 \\
\hline Female & $115(50.9)$ & $111(49.1)$ & $226(64.2)$ & \\
\hline \multicolumn{5}{|c|}{ Socio-economic status } \\
\hline Upper & $45(42.5)$ & $61(57.5)$ & $106(30.1)$ & $0.028 *$ \\
\hline Middle & $132(57.1)$ & $99(42.9)$ & $231(65.6)$ & \\
\hline Lower & $6(40.0)$ & $9(60.0)$ & $15(4.3)$ & \\
\hline \multicolumn{5}{|c|}{ Period of living with HIV } \\
\hline$>10$ Years & $52(50.0)$ & $52(50.0)$ & $104(29.5)$ & 0.714 \\
\hline$\leq 10$ Years & $131(52.8)$ & $117(47.2)$ & $248(70.5)$ & \\
\hline \multicolumn{5}{|c|}{ Patients on HAART } \\
\hline No & $28(70.0)$ & $12(30.0)$ & $40(11.4)$ & $0.020 *$ \\
\hline Yes & $155(49.7)$ & $157(50.3)$ & $312(88.6)$ & \\
\hline \multicolumn{5}{|c|}{ Self-reported medical conditions } \\
\hline No & $139(52.5)$ & $110(48.5)$ & $265(75.3)$ & 0.733 \\
\hline Yes & $44(50.6)$ & $43(49.4)$ & $87(24.7)$ & \\
\hline
\end{tabular}


Self-rated oral health, Self-reported oral problems, medical conditions and HAART use in PLWHA in Nigeria

The subjects' self-rated oral health was excellent in $18.5 \%$, good in $52.8 \%$, fair $(26.1 \%)$, and poor $(2.6 \%)$. A significant proportion $(68.7 \%)$ reported an oral problem in the past one year. Only $88(25 \%)$ had utilized the dental clinic in the preceding year, although more than half, 217(61.6\%) expressed a self-perceived need for dental treatment. Overall, only about a third
$130(30.6 \%)$ of the subjects had visited the dentist before while $222(63.1 \%)$ had never visited. Majority, $312(88.6 \%)$ were on Highly active anti-retroviral therapy (HAART). Self-reported oral problems were reported in $222(71.2 \%)$ patients on HAART and $20(50 \%)$ of those who were not on HAART. $[\mathrm{P}=0.029]$. The OHRQoL was significantly poor among those with self-reported oral problems $(\mathrm{P}<0.001)$, perceived need for dental treatment $(\mathrm{P}<0.001)$, dental visit in the past year $(\mathrm{P}<0.001)$, presence of oral lesions $(\mathrm{P}=0.021)$ and DMFT $(\mathrm{P}<0.005)$

Table 4: Association of poor OHRQoL with oral hygiene practices and clinical findings

\begin{tabular}{|c|c|c|c|c|}
\hline & $\begin{array}{l}\text { Good } \\
\text { OHRQoL } \\
\text { N(O) }\end{array}$ & Poor OHRQoL & $\begin{array}{l}\text { Total } \\
\text { N }(\%)\end{array}$ & P-value \\
\hline \multicolumn{5}{|c|}{ Self-reported oral problems in the last one year } \\
\hline Toothache & $15(28.8)$ & $37(71.2)$ & $52(14.8)$ & $<0.001 *$ \\
\hline $\begin{array}{l}\text { Swelling of the } \\
\text { mouth/face }\end{array}$ & $3(42.9)$ & $4(57.1)$ & $7(2.0)$ & \\
\hline $\begin{array}{l}\text { Sensitivity to } \\
\text { hot/cold drinks }\end{array}$ & $23(60.5)$ & $15(39.5)$ & $38(10.8)$ & \\
\hline Mouth Ulcer & $4(66.7)$ & $2(33.3)$ & $6(1.7)$ & \\
\hline Mouth Odour & $10(47.6)$ & $11(52.4)$ & $21(6.0)$ & \\
\hline Mobile Teeth & $1(16.7)$ & $5(83.3)$ & $6(1.7)$ & \\
\hline Hole in Tooth & $22(28.2)$ & $56(71.8)$ & $78(22.2)$ & \\
\hline Bleeding Gums & $18(52.9)$ & $16(47.1)$ & $34(9.7$ & \\
\hline Total Oral problems & $96(39.7)$ & $146(60.3)$ & $242(68.7)$ & \\
\hline None & $87(79.1)$ & $23(20.9)$ & $110(31.3)$ & \\
\hline \multicolumn{5}{|c|}{ Perceived need of dental treatment } \\
\hline No & $105(77.8)$ & $30(22.2)$ & $135(38.4)$ & $<0.001 *$ \\
\hline Yes & $78(35.9)$ & $139(64.1)$ & $217(61.6)$ & \\
\hline \multicolumn{5}{|c|}{ Dental visit in the past year } \\
\hline No & $153(58.0)$ & $111(42.0)$ & $264(75.0)$ & $<0.001 *$ \\
\hline Yes & $30(34.1)$ & $58(65.9)$ & $88(25.0)$ & \\
\hline \multicolumn{5}{|c|}{ Presence of Oral lesions } \\
\hline Hyperpigmentation & $1(25.0)$ & $3(75.0)$ & $4(1.1)$ & $0.021 *$ \\
\hline NUG & $0(0.0)$ & $1(100.0)$ & $1(0.3)$ & \\
\hline Apthous Ulcer & $0(0.0)$ & $3(100.0)$ & $3(0.9)$ & \\
\hline LGE & $6(85.7)$ & $1(14.3)$ & $7(2.0)$ & \\
\hline Candidiasis & $5(83.3)$ & $1(16.7)$ & $6(1.7)$ & \\
\hline None & $171(51.7)$ & $160(48.3)$ & $331(94.0)$ & \\
\hline \multicolumn{5}{|l|}{ OHIS Grade } \\
\hline Good & $43(45.7)$ & $51(54.3)$ & $94(26.7)$ & 0.268 \\
\hline Fair & $107(53.0)$ & $95(47.0)$ & $202(57.4)$ & \\
\hline Poor & $33(58.9)$ & $23(41.1)$ & $56(15.9)$ & \\
\hline \multicolumn{5}{|l|}{ DMFT Grade } \\
\hline No Caries & $103(61.3)$ & $65(38.7)$ & $168(47.7)$ & $0.005 *$ \\
\hline Very Mild & $23(44.2)$ & $29(55.8)$ & $52(14.8)$ & \\
\hline Mild & $36(50.0)$ & $36(50.0)$ & $72(20.5)$ & \\
\hline Moderate & $12(40.0)$ & $18(60.0)$ & $30(8.5)$ & \\
\hline Severe & $9(30.0)$ & $21(70.0)$ & $30(8.5)$ & \\
\hline
\end{tabular}

Eighty-six respondents (25.4\%) gave a history of an underlying medical conditions. (Table 4).

In the logistic regression model, all the variables that were statistically significant in the Chi-square and spearman correlation tests were entered into a regression model to determine the factors that were independently associated with poor OHRQoL after controlling for potential confounders were. The independent factors were the perceived need for dental treatment $(\mathrm{p}<0.001$; OR:95\%C.I:4.774), use of HAART $(\mathrm{p}=0.037$; OR:95\%C.I:2.392), and higher DMFT ( $\mathrm{p}=0.038$; OR: 95\%C.I: 1.226). Subjects with a perceived need of dental treatment had a higher Odds $4.77(2.79-8.16)$ of reporting a poor OHRQoL. (Table 5) 
Table 5. Logistic regression model of factors associated with a poor OHRQoL

\begin{tabular}{|c|c|c|c|c|}
\hline \multirow[t]{2}{*}{ Independent variables } & \multirow{2}{*}{$\begin{array}{l}\text { Adjusted } \\
\text { OR }\end{array}$} & \multirow{2}{*}{$\begin{array}{l}P \text { - } \\
\text { value }\end{array}$} & \multicolumn{2}{|c|}{ 95\% C.I for OR } \\
\hline & & & Lower & Upper \\
\hline SES & 0.804 & 0.094 & 0.623 & 1.038 \\
\hline $\begin{array}{l}\text { Perceived need for dental } \\
\text { treatment }\end{array}$ & 4.716 & $0.000^{*}$ & 2.783 & 7.989 \\
\hline Dental visit in the past year & 1.325 & 0.355 & 0.729 & 2.408 \\
\hline $\begin{array}{l}\text { Presence of oral problems in the } \\
\text { last one year }\end{array}$ & 0.888 & $0.005^{*}$ & 0.817 & 0.965 \\
\hline $\begin{array}{l}\text { Presence of oral lesions } \\
\text { associated with HIV/AIDS }\end{array}$ & 0.773 & 0.600 & 0.295 & 2.025 \\
\hline Patients on HAART & 2.392 & $0.037 *$ & 1.053 & 5.432 \\
\hline DMFT Grade & 1.226 & $0.038^{*}$ & 1.012 & 1.486 \\
\hline Constant & 0.465 & 0.204 & & \\
\hline
\end{tabular}

\section{Discussion}

The human immunodeficiency virus infection has remained a devastating disease of public health importance with an impact on the oral health of people living with HIV/AIDS (PLWHA). The present study determined the association between oral health and the quality of life and the factors affecting OHRQoL among HIV positive patients in Nigeria. This was in order to facilitate improved provision of dental care for such individuals.

The study had some limitations such as the convenience sample that was used which might have encouraged the participation of individuals that were more concerned about their oral health, hence may not be fully representative of all PLWHA in Nigeria. The cross-sectional design of the study also makes it difficult to establish a cause-effect relationship between oral health and quality of life. Also, the self-reporting of some data in the study may have recall bias and affected the accuracy of the responses. Nevertheless, the study had many strengths. To the best of our knowledge, it is the first published study on the oral health related quality of life in PLWHA in Nigeria. Furthermore, this study has an ethnic diversity, a relatively large sample from two HIV treatment centres in Nigeria, which gives a broad understanding of the important associations between oral health and the health related quality of life among PLWHA in Nigeria.

The low prevalence of oral health impact on the quality of life of PLWHA in the present study contrasts when compared with other studies ${ }^{6,31}$. A higher prevalence of $62.6 \%$ was reported among low-income HIV positive adults in the $\mathrm{US}^{6}$ and a prevalence of $33.9 \%$ was reported among HIV patients in Malaysia ${ }^{31}$. The differences observed between our study and theirs may stem from the difference in the socioeconomic status (SES), as most of the subjects in the two study centres in the present study belonged to the upper and middle socioeconomic class and this may account for the low prevalence of oral impact in the present study. The negative impact of SES on the quality of life of HIV/ AIDS patients has been documented previously ${ }^{32}$. The observation of physical pain ("painful aching" and" uncomfortable chewing") as the most prevalent oral health impact in the present study, may be due to the high proportion of self-reported oral problems by the patients namely toothache, swelling from the mouth/ face, mobile teeth and hole in the teeth which are often symptomatic oral conditions. This is comparable to the finding in the Portuguese study by Santo et al, ${ }^{33}$ in which majority of the respondents also reported an impact in the domain of physical pain and this was attributed to their discomfort while eating food. Our finding is however in contrast to the Malaysian study ${ }^{31}$ in which the most affected oral health domain was psychological discomfort. In that study, the most common impact reported was the feeling of discomfort due to food getting stuck in between teeth or dentures.

The use of HAART has been reported to significantly reduce the prevalence of oral lesions and opportunistic illnesses associated with HIV and mortality ${ }^{34}$. This is consistent with the low prevalence of oral lesions $(5.9 \%)$ in the present study which however contrasts with the South African study in which more than 50\% of the PLWHA had two or more oral lesions ${ }^{22}$. However, none of the participants in the South African study was on antiretroviral treatment unlike the present study 
where majority were on HAART. It has been reported that PLWHA with oral lesions have significantly poor OHRQoL than PLWHA without oral lesions ${ }^{35}$ and may negatively impact the OHRQoL ${ }^{30}$. Oral lesions can alter facial appearance, speech, causing chewing, swallowing difficulty and pain ${ }^{36}$. Thus, poor oral function will exacerbate nutritional problems that may further affect their quality of life ${ }^{35,36}$.

Despite the low prevalence of oral lesions in the present study, HAART use by patients was independently associated with poor OHRQoL which was baffling to us. This raises some valid concerns about some potential side effects of HAART on oral health in the course of managing HIV/AIDS infection. Whilst, HAART is beneficial in reducing the prevalence of oral lesions, the type of HAART administered to patients could also, influence the OHRQoL. This may be influenced by the reduced immunologic response and decreased salivary function with the continuous use of the medications. Again, the reason for the finding may not be too farfetched considering the significantly higher prevalence of self-reported oral problems in patients that were on HAART $(71.2 \%)$ compared to those not on HAART $(50 \%)$. The presence of painful oral lesions and conditions can contribute to ineffective or infrequent tooth brushing leading to discomfort and disability, masticatory inefficiency and consequently the OHRQoL.

The prevalence of dental caries in the present study was relatively low (mean DMFT of 1.8) when compared to other studies in HIV positive populations where the mean DMFT varied from 8.7 in Australia ${ }^{7}$ to 16.9 in Portugal $^{33}$ and 18.8 in Brazil $^{37}$. This may be reflective of the low prevalence of dental caries in the general Nigerian population ${ }^{38}$. The low DMFT in this study could also be attributed to the relatively good oral hygiene habits by the subjects as more than half of them had a fair oral hygiene status. Nevertheless, the unmet need from the untreated carious lesions is still somewhat a course for concern because higher DMFT scores may be reflective of higher morbidity in terms of pain and/ or swelling.

The significantly poorer OHRQoL among those with self-perceived need of dental treatment is consistent with previous studies ${ }^{22,31}$. The awareness of oral health problems and the need to access treatment may be seen by the patients to have an impact on their overall health. Although, about two thirds $(61.4 \%)$ of the patients reported at least one dental problem that needed professional attention, only about half had actually visited the dentist. This reflects an unmet need among the PLWHA and their inadequate utilization of dental services which buttresses the fact that having dental issues alone is not sufficient reason for an individual to visit the dental clinic. There are other factors that could serve as potential barriers to accessing care such as finances and unavailability of clinics which were among the factors highlighted in our previous study ${ }^{39}$.

In agreement with previous studies ${ }^{22,40}$, this study identified more females compared to males. Women have been reported to be more expressive and concerned about their oral health than men as it causes them pain and embarrassment ${ }^{40}$. In addition, females are more likely to relate their oral health to their appearance and quality of life.

\section{Conclusion}

Within the limitations earlier highlighted in this study, the domain of physical pain had the highest oral health impact, while the perceived need for dental treatment, HAART use and higher caries index were contributory to poor OHRQoL. Our findings highlight the importance of routine dental check-up for PLWHA particularly among those on HAART and the role of dentists in their interdisciplinary management.

\section{Conflict of interest}

The authors declare no conflict of interest.

\section{Source of funding}

None.

\section{Acknowledgement}

The APIN Clinics of the two study centers for their support.

\section{References}

1. World Health Organization. Global Health Observatory (GHO) data HIV/AIDS. (2018a). Retrieved from https://www.who.int/gho/hiv/en/

2. UNAIDS. AIDSInfo Number of people living with HIV. (2018). Retrieved from https://aidsinfo.unaids. org/

3. Avert. Global HIV and AIDS Statistics. 2020 Retrieved from Global information and education on HIV and AIDS website: https://www.avert.org/global-hivand-aids-statistics

4. World Health Organization. WHO Africa Health Topics - HIV/AIDS. (2018b). Retrieved from https:// www.afro.who.int/health-topics/hivaids

5. National Agency for the control of AIDS (NACA). 
Revised National HIV and AIDS Strategic Framework 2019-2021 Future directions for the HIV/AIDS response in Nigeria. 2018 Retrieved from https:// naca.gov.ng/wp-content/uploads/2019/03/NATIONAL-HIV-AND-AIDS-STRATEGIC-FRAMEWORK-1.pdf

6. Tomar SL, Pereyra MML. Oral health-related quality of life among low-income adults living with HIV. Journal of Public Health Dentistry. 2011;71(3), 241-247.

7. Liberali SA, Coates EA, Freeman AD, Logan RM, Jamieson LMG. Oral conditions and their social impact among HIV dental patients, 18 years on. Aust Dent J. 2013; 58(1), 18-25.

8. Umeizudike KA, Ayanbadejo PO, Savage KO. Relationship of oral hygiene status and practices with oral lesions in a group of HIV positive patients.pdf. Nig Dent J. 2012; 20(1), 31-36.

9. Eweka OM., Agbelusi GA,Odukoya O. Prevalence of oral lesions and the effects of HAART in adult HIV patients attending a tertiary hospital in Lagos , Nigeria. Open Journal of Stomatology. 2012; 2, 200-205.

10. Hegde MN, Hegde ND, Malhotra A. Prevalence of oral lesions in HIV infected adult population. BioDiscovery. 2012 (4), 1-5. https://doi.org/10.7750/BioDiscovery.2012.4.3

11. Patil N, Chaurasia VR., Babaji P, Ramesh D, Jhamb $\mathrm{K}$, Sharma, AM. The effect of highly active antiretroviral therapy on the prevalence of oral manifestation in human immunodeficiency virus-infected patients in. Eur J Dent.2019; 9(1), 47-52. https://doi.org/10.4103/13057456.149640

12. Velegraki A, Paikos S, Economopoulou P, Stefaniotis T, Papanikolaou IS. HIV Disease/Oral Medicine Effect of PI-HAART on the prevalence of oral lesions in HIV-1 infected patients. A Greek study. Oral Diseases. 2004;10, 145-150.

13. Mary EO, Abiola OA, Titilola G, Mojirayo OO, SA. Prevalence of HIV related oral lesions in people living with HIV and on combined antiretroviral therapy: a Nigerian experience. Pan Afr Med J. 2018 14(31), 180. https://doi.org/10.11604/pamj.2018.31.180.13574

14. Kumar JV, Baghirath PV, Naishadham PP, Suneetha S, Suneetha, SP. Relationship of long-term highly active antiretroviral therapy on salivary flow rate and CD4 Count among HIV-infected patients. J Oral Maxillofac Pathol. 2015; 19(1), 58-63. https://doi. org/10.4103/0973-029X.157203.

15. Broder S. The development of antiretroviral therapy and its impact on the HIV-1/AIDS pandemic. Antiviral Research. 2010 85, 1-18. https://doi.org/10.1016/j. antiviral.2009.10.002
16. Oladokun RE, Okoje VN, Osinusi KOO. Oral lesions and their association with CD4 count and viral load in HIV positive Nigerian children. Oral Health Dent Manag. 2013; 12(4), 200-204.

17. Braz DR. HIV-1 Impact On Oral Health-Related Hiv1 Impact On Oral Health-Related. 2015 Retrieved from https://repositorio.ul.pt/bitstream/10451/25511/1/ ulfmd02858_tm_David_Braz.pdf

18. Anup N, Sikka M, Biswas G, Shravani G, Jain P, Sontakke P. Oral health related quality of life among HIV patients at antiretroviral therapy center government hospital, Jaipur. Indian Assoc Public Health Dent. 2015; 13(2), 148-151. https://doi.org/10.4103/23195932.159051

19. Slade GD. (1997). Measuring Oral Health and Quality of Life. Edited by Gary D. Slade.

20. Locker D. Measuring oral health: a conceptual framework. Community Dental Health.1988; 5, 3-18.

21. Amalia C, Silva B, Grando LJ, Maria S, Fabro L. Oral health related to quality of life in patients with stomatological diseases. Stomatologija, Baltic Dental and Maxillofacial Journal. 2015; 17(2), 48-53.

22. Bajomo AS, Ayo-yusuf OA, Rudolph MJ, Tsotsi NM. Impact of oral lesions among South African adults with HIV / AIDS on oral health-related quality of life. Journal of Dental Sciences. 2013; 8(4), 412-417. https:// doi.org/10.1016/j.jds.2013.04.011

23. Vieira C, Lins L, Sarmento VA, Netto EM, Brites C. Oral health and health-related quality of life in HIV patients. BMC Oral Health. 2018; 18(151).

24. Jeganathan S, Batterham M, Begley K, Purnomo J, Houtzager L. Predictors of oral health quality of life in HIV-1 infected patients attending routine care in Australia. J Public Health Dent. 2011; 71, 248-251. https:// doi.org/10.1111/j.1752-7325.2011.00257.x

25. Centers for Disease Control and Prevention. Vital Signs: HIV Prevention Through Care and Treatment — United States. MMWR, 2011; pp. 60(47);1618-1623. Retrieved from https://www.cdc.gov/mmwr/preview/ mmwrhtml/mm6047a4.htm

26. Oyedeji GA. Socioeconomic and cultural background of hospitalized children in Ilesa. Niger J Paediatr 1985; 12, 111-117.

27. Greene JC, Vermillion JR. The Simplified Oral Hygiene Index. J Am Dent Assoc. 1964; 68, 7-13. https:// doi.org/10.14219/jada.archive.1964.0034

28. World Health Organisation. Oral Health Survey. Basic Methods (fifth edition) 2013.pp 74.

29. No authors listed. Classification and diagnostic criteria for oral lesions in HIV infection. EC-Clearinghouse on Oral Problems Related to HIV Infection and 
WHO Collaborating Centre on Oral Manifestations of the Immunodeficiency Virus. J Oral Pathol Med.1993; 22(7), 289-91.

30. Yengopal VNS. Do oral lesions associated with HIV affect quality of life? Oral Surg Oral Med Oral Pathol Oral Radiol Endod. 2008; 106(1), 66-73. https://doi. org/10.1016/j.tripleo.2007.12.024.

31. Mohamed N, Saddki N, Yusoff A. Association among oral symptoms, oral health-related quality of life, and health-related quality of life in a sample of adults living with HIV/AIDS in Malaysia. BMC Oral Health. 2017; 17(1), 119. https://doi.org/10.1186/s12903-0170409-y

32. Soares, G., Garbin, C. A., Rovida, T. A., \& Garbin, A. J. (2014). Oral health associated with quality of life of people living with HIV/AIDS in Brazil. Health and Quality of Life Outcomes 2014; 12(1), 28.

33. Santo AE, Tagliaferro EP, Ambrosano GM, Meneghim MC. Dental status of Portuguese HIV+ patients and related variables: a multivariate analysis. Oral Dis. 2010; 16(2), 176-184. https://doi.org/10.1111/ j.1601-0825.2009.01622.x

34. Buchacz K, Baker RK, Palella FJ Jr, Chmiel JS, Lichtenstein KA, Novak RM, et al. AIDS-defining Opportunistic Illnesses in US Patients, 1994-2007: A Cohort Study. AIDS. 2010; 24(10), 1549-1559. https:// doi.org/10.1097/QAD.0b013e32833a3967
35. Khan SA, Moorthy J, Omar H. People living with HIV/AIDS (PLWHA) and HIV/AIDS associated oral lesions; a study in Malaysia. BMC Public Health. 2012; 12(1), 850.

36. Sroussi HY. Changes in the pattern of oral lesions associated with HIV infection:implications for dentists. J Can Dent Assoc. 2007; 73(10), 949-52.

37. Pinheiro A, Marcenes W, Zakrzewska JM. Dental and oral lesions in HIV infected patients: a study in Brazil. Int Dent J. 2004 54(3), 131-137. https://doi. org/10.1111/j.1875-595x.2004.tb00268.x

38. Olabisi AA, Udo UA, Ehimen UG, Bashiru BO, Gbenga OO, Adeniyi AO. Prevalence of dental caries and oral hygiene status of a screened population in Port Harcourt, Rivers State, Nigeria. I Int Soc Prevent Communit Dent 2015;5:59-63

39. Umeizudike KA, Daramola O, Osagbemiro BB, Adeyemo T. Pattern of utilization of dental services and oral self-care practices of people living with HIV/AIDS in two tertiary health institutions in Nigeria. $N$ Niger $J$ Clin Res. 2019; 8, 84-90. https://doi.org/10.4103/nnjcr. nnjcr_35_18

40. Inglehart MR, Silverton SF. Oral health-related quality of life: does gender matter? In: Inglehart MR, Bagramian RA, eds. Oral Health-Related Quality of Life. Chicago: Quintessence. 